Research, Society and Development, v. 9, n. 10, e6909109163, 2020

(CC BY 4.0) | ISSN 2525-3409 | DOI: http://dx.doi.org/10.33448/rsd-v9i10.9163

\title{
Complexidade e escolarização: tramando tensionamentos
}

Complexity and schooling: plotting tension

Complejidad y escolaridad: trazando tensión

Recebido: 08/10/2020 | Revisado: 11/10/2020 | Aceito: 13/10/2020 | Publicado: 14/10/2020

\section{Celina Saideles Pires}

ORCID: https://orcid.org/0000-0002-1927-324X

Colégio Nossa Senhora de Fátima, Brasil

E-mail: celina.saideles@gmail.com

Fernanda Monteiro Rigue

ORCID: https://orcid.org/0000-0003-2403-7513

Universidade Federal de Santa Maria, Brasil

E-mail: fernanda_rigue@ hotmail.com

\section{Resumo}

O presente estudo tensiona a possibilidade do desenvolvimento de olhares, posturas e ações complexas em meio a instâncias escolarizantes - principalmente no que tange ao exercício da docência. Realiza uma revisão bibliográfica de caráter qualitativo (André, 2013), onde toma relevo o pensamento da Teoria da Complexidade de Edgar Morin (2000, 2005, 2014, 2015), bem como os estudos da escolarização em Corrêa (2006), Corrêa e Preve (2011) e Rigue (2017, 2020). Resulta do empenho de investigação a compreensão de que as garantias da escolarização (De la fare \& Corrêa, 2015), que estão no entorno do modo como funciona a instituição escolar, dificultam o desenvolvimento de um olhar e postura complexa que poderia vir a potencializar a compreensão de uma aprendizagem mais significativa no que tange a formação dos estudantes. Sendo, portanto, um grande desafio a implementação de premissas e compreensões mais amplas da Teoria da Complexidade nos ambientes escolares, quando se trata da educação escolar no Brasil.

Palavras-chave: Escolarização; Complexidade; Docência.

\footnotetext{
Abstract

The present study stresses the possibility of developing complex looks, postures and actions in the midst of schooling instances - especially with regard to the exercise of teaching. It carries out a qualitative bibliographic review (André, 2013), where the thought of Edgar Morin's Theory of Complexity $(2000,2005,2014,2015)$ is highlighted, as well as the studies of
} 
schooling in Corrêa (2006), Corrêa and Preve (2011) and Rigue (2017, 2020). It results from the research effort the understanding that the guarantees of schooling (De la fare \& Corrêa, 2015), which are around the way the school institution works, hinder the development of a complex look and posture that could potentially enhance the understanding of more meaningful learning in terms of student training. Therefore, it is a great challenge to implement premises and broader understandings of Complexity Theory in school environments, when it comes to school education in Brazil.

Keywords: Schooling; Complexity; Teaching.

\section{Resumen}

El presente estudio destaca la posibilidad de desarrollar miradas, posturas y acciones complejas en medio de instancias de escolarización, especialmente en lo que respecta al ejercicio de la docencia. Se realiza una revisión bibliográfica cualitativa (André, 2013), donde se destaca el pensamiento de la Teoría de la Complejidad de Edgar Morin (2000, 2005, 2014, 2015), así como los estudios de escolarización en Corrêa (2006), Corrêa y Preve. (2011) y Rigue (2017, 2020). Resulta del esfuerzo de investigación el entendimiento de que las garantías de escolarización (De la fare \& Corrêa, 2015), que giran en torno al funcionamiento de la institución escolar, dificultan el desarrollo de una mirada y una postura complejas que potencialmente podrían potenciar la comprensión de un aprendizaje más significativo en términos de formación de los estudiantes. Por lo tanto, es un gran desafío implementar premisas y comprensiones más amplias de la Teoría de la Complejidad en los entornos escolares, cuando se trata de la educación escolar en Brasil.

Palabras clave: Escolaridad; Complejidad; Docencia.

\section{Introdução}

A sociedade civilizada ocidental demandou, historicamente, de uma série de instituições que a deram uma espinha dorsal para o bom funcionamento: família, prisão, escola, entre outros. Dentre essas instituições a escola, acabou se tornando marco da inserção dos sujeitos na realidade comunitária.

Os estudos de Michel Foucault (2015) se debruçaram em pensar as estratégias de disciplinamento que balizaram o funcionamento e a estrutura das escolas - desde sua criação até o seu funcionamento. Desde a arquitetura das salas de aula, até o ordenamento dos currículos, das disciplinas e dos exames. Além disso, se tratarmos do aparecimento e do funcionamento das escolas no âmbito da América Latina, em especifico do Brasil, por exemplo, é possível 
verificarmos nos estudos de Corrêa (2006) e Rigue (2017; 2020), alguns dos tantos investimentos para que ela fosse possível para todos e cada um.

Os alicerces que tornaram possível a escola enquanto instituição, agregaram uma série de elementos indispensáveis para seu funcionamento: professores, alunos, materiais didáticos, métodos avaliativos, entre outros. Uma série de “[...] garantias da escolarização" (De la fare \& Corrêa, 2015). Acerca das garantias De La Fare e Corrêa (2015) escrevem que:

A educação escolar, seja em escolas públicas ou particulares, é controlada pelas leis da educação nacional e submetida a uma série de limites que tentam garantir a efetividade do processo educativo nesse âmbito. Esses limites, que chamamos de garantias da escolarização, são constituídos por uma série de medidas que visam fazer funcionar a educação em seu registro escolar, ou seja, delimitam os processos educacionais possíveis a um corpo coerente de funcionamento nomeado escola. (...) Entender essas garantias é uma questão um pouco exigente, pois demanda prestar atenção aos mecanismos que a escola põe em funcionamento. Esses mecanismos têm a propriedade de serem muito familiares, a ponto de estarem naturalizados por sua presença em nossas vidas desde que nascemos, seja pela via da convivência familiar e sua relação com a escola, seja pela presença, cada vez mais antecipada das crianças na escola (p. 342).

Estados e municípios também ficaram encarregados de fazer valer o alcance dessa instituição escolar a crianças e jovens, nos mais diferentes contextos e territórios do Brasil levando em consideração a significativa extensão do nosso território geográfico e espacial.

Tendo em vista essa realidade específica, suas peculiaridades e nuances, o presente estudo realiza uma revisão bibliográfica, de caráter qualitativo (André, 2013), que tensiona a possibilidade do desenvolvimento de olhares, posturas e ações complexas em meio a instâncias escolarizantes - principalmente no que tange ao exercício da docência.

Por sua vez, é preciso perguntar por que lançamos mão da Teoria da Complexidade de Edgar Morin para tensionar a escolarização? O fazemos por pensar a referida teoria como uma brecha que abre a possibilidade de produzir espaços onde crianças e jovens tenham a chance de estarem implicadas na vida, nos modos de existência as quais a escolarização supostamente encontra-se envolvida. Processos e relações pedagógicas que deem a possibilidade do conhecimento em mobilização como propulsor de pensamentos e reflexões ativas.

\section{Metodologia}

Este estudo trata-se de uma revisão bibliográfica, de caráter qualitativo (André, 2013), a qual reúne estudos contemporâneos, principalmente localizados no território brasileiro, que pensam a educação escolar e seu aparecimento e funcionamento (Corrêa \& Preve, 2011; Corrêa, 2006; Rigue, 2017, 2020). Nesse mesmo tom, é tramado um movimento teórico conceitual que 
pensa a Teoria da Complexidade de Edgar Morin (2000, 2005, 2014, 2015) em meio ao que temos vivido na escolarização brasileira.

Primeiro, apresentamos as contingências que demarcam a escola no Brasil. Em seguida, apontamos alguns dos principais elementos de Morin (2000, 2005, 2014, 2015) acerca da sua Teoria da Complexidade. Por fim, nos colocamos a espreita para desenvolver um exercício teórico e conceitual que tensione a seguinte pergunta: É possível desenvolver olhares e posturas complexas em meio a instâncias escolarizantes?

\section{Resultados e Discussão}

\subsection{Escolarização}

A escolarização aparece como válvula que faz a passagem de um regime de disciplina para um regime de controle. À escola cabe o papel de preparadora dos corpos, de máquina de condicionamento, adequada a produção dos treináveis. Os treináveis são os que podem ficar soltos, que têm liberdade de escolha e vontade própria, adequados para o controle a céu aberto. Podemos escolher qualquer profissão, qualquer candidato, qualquer produto nas prateleiras, qualquer estilo de vida... Qualquer escolha deve ser um movimento de capital e qualquer movimento deve gerar dados passíveis de serem reunidos em função de marcadores pessoais, como o número do $\mathrm{CPF}$, o endereço eletrônico, os cartões de banco ou uma senha de acesso. Aí se vê desenhar um dos traços mais marcantes dos efeitos da Educação escolar vinculada ao comunicacional: uma conquista de liberdade com preço em dinheiro (Corrêa, 2006, p. 151).

A Educação desenvolvida nos ambientes escolarizados, “[...] é constantemente produzida pelas políticas e iniciativas Governamentais" (Rigue, Amestoy \& Veiga, 2019, p. 117). No Brasil, o modo pensante da escola pública é afetada diretamente pelos governos que adentram o poder nacional. Isso quer dizer que conforme muda a perspectiva política ideológica dos partidos que ocupam o poder de decisão, a educação escolar é diretamente afetada.

Para pensar o sistema educacional como um todo, pode considerar que o mesmo:

[...] abriga a rede escolar de alcance nacional (escolas de educação básica e cursos universitários de formação inicial) e intuições específicas para a produção teórica (cursos de pós-graduação, núcleos e grupos de pesquisas e as instâncias técnicas de onde derivam as formulações das leis e recomendações da política nacional) (Corrêa \& Preve, 2011, p. 183).

Esse sistema educativo,

[...] tornou-se responsável por uma educação que sobrepassa, em muito, o ensino dos conteúdos escolares fixados nos tempos ditatoriais e reforçados a exaustão em tempos de 
Research, Society and Development, v. 9, n. 10, e6909109163, 2020

(CC BY 4.0) | ISSN 2525-3409 | DOI: http://dx.doi.org/10.33448/rsd-v9i10.9163

abertura política pela correspondência aos conteúdos dos exames vestibulares. Para além desses conteúdos, ela deve dar conta de temas transversais e cumprir sua função social. Tornou-se hábito, na maioria dos trabalhos acadêmicos e dos documentos oficiais, terminar em gasosas e indefinidas recomendações que no campo discursivo assumem ares de objetividade. Só que isso tem se restringido a locuções formuladas como recomendações. É evidente, nesses documentos, a desconsideração dos meios pelos quais se atingiria a consecução de qualquer um desses ideais. A escola é forçada por todo o sistema educacional e por toda a opinião pública a cumprir o que nunca deixou de prometer e se dizer capaz: a educação de todos (Corrêa \& Preve, 2011, p. 193-194).

$\mathrm{O}$ agenciamento da escola enquanto instituição comporta mecanismos que se combinam com intuito de desenvolver habilidades e competências valorizadas no meio social e da sociedade do consumo. Nesse cenário, crianças e jovens são produzidas para desempenhar funções que caminham para uma série de fins, principalmente: o fim de girar economia, padronizar condutas e regular modos e/ou formas de vida. Mas não nos entendam mal, não queremos dizer que a educação escolar é má. Ao contrário, que seu modo de acontecer e afetar o dia a dia de crianças e jovens, nem sempre encontra-se vinculado aos discursos presentes nas orientações pedagógicas que balizam os documentos orientadores da prática educativa.

No final das contas, o que os estudantes têm vivido na prática é: conteúdo dado, conteúdo estudado. Nas primeiras aulas são desenvolvidas explicações teóricas acerca de determinados conteúdos. Essas explicações são seguidas de alguns exemplos, que na maioria dos casos envolvem resolução de exercícios teóricos, seguidos de resolução de problemas presentes em uma lista com aproximadamente dez problemas para 'fixação'.

Essas questões dizem do quanto o trabalho pedagógico empreendido pelo professor em sala de aula encontra-se enclausurado dentro da promessa de que todo ensino precisa e pode ser convertido, invariavelmente, em aprendizagem na escola. Contingência que retroalimenta o âmbito do dualismo ensino-aprendizagem, bem como todas as suas engrenagens e dispositivos que estabelecem uma subjetivação como a hegemonia de estratégias pedagógicas desconexas da vida das crianças e dos jovens (Rigue, 2020, p. 262-263).

O fim desse empenho é a realização de provas e exames. São nessas provas e nesses exames que crianças e jovens precisam mostrar que 'aprenderam' a reproduzir os conteúdos explicados nas aulas anteriores. Caso o estudante, não consiga obter um resultado satisfatório nesse jogo de resolver provas e exames, ele acaba sendo submetido a uma série de novas aulas e resolução de questões para, quem sabe assim, obter um resultado satisfatório.

Corrêa e Preve (2011) escrevem que:

Em uma sala de aula, esteja o aluno sendo alfabetizado, aprendendo a fazer contas ou conteúdos dessa ou daquela disciplina, a ação constante e que atravessa todos esses 
fazeres educacionais é a fixação do estudante à carteira escolar. Aprender, antes de ser a assimilação de conteúdos, implica num exercício constante e invariável de imobilização do corpo. Independentemente dos conteúdos, que podem ou não ser assimilados, é cada vez mais comum jovens que terminaram o Ensino Fundamental, serem classificados como analfabetos funcionais - a ação educacional da escola, o que se aprende, é a contenção das forças de expansão do corpo em situações de ensino-aprendizagem. Nesse jogo, os conteúdos, como cúmulo de conceitos e modos de percepção (científicos) fixados nos conteúdos escolares, contribuem para tomar o lugar do pensamento na medida em que a escola se propõe a ensinar a pensar (p. 183-184).

Nesse modo de operar da escola o exame/prova é, conforme Morgenstern \& Camillo (2018) como um passaporte: "Ele classifica, define, determina e autoriza que espaço ocupar na configuração social ou quais desses espaços 'deseja-se' alcançar, que direitos temos ou não temos nesse jogo social” (p. 94). As tecnologias que se aliam nos regimes disciplinares e de controle visam fins específicos. Categorizações que dizem dos modos e comportamentos esperados das crianças e dos jovens que outrora serão adultos. Isso quer dizer que a escola ocupa um lugar de destaque no cenário e na engrenagem de funcionamento social, enquanto promotora e propulsora de subjetividades específicas, consumidoras e consumidas, que estão permanentemente vinculadas “[...] à presença de uma prospecção de futuro expressiva acerca da formação dos estudantes vinculados às escolas no Brasil” (Rigue, 2020, p. 261).

Dentro desse prisma de compreensão da escola, é possível tensionar: e agora, o que resta a nós, meros mortais, inseridos nesse engendramento?

\subsection{Complexidade}

A Teoria da Complexidade foi desenvolvida por Edgar Morin em meados da década de 70. O autor publicou uma série de obras preocupadas em desconstruir os cânones das certezas, colocando-as em dissipação. Para Morin (2000) a educação precisa “[...] promover a "inteligência geral" apta a referir-se ao complexo, ao contexto, de modo multidimensional e dentro da concepção global”' (p. 39).

Conforme já apresentamos anteriormente, os processos educativos existentes na escola abarcam uma série de sujeitos, educandos e educadores que a constituem: estudantes, professores, funcionários, entre outros. Desse modo, esse espaço habitado é de veras complexo (Morin, 2005). Muitos agentes precisam convergir para colocarem em prática as premissas que norteiam os fins da escolarização. Essas premissas, na maioria dos casos demandam um conhecimento enquanto verdade - paradigma. Enquanto certeza sobre determinado saber. Por sua vez, com Edgar Morin (2000), entende-se a importância da incerteza do conhecimento: 
Quantas fontes, quantas causas de erros e de ilusão múltiplas e renovadas constantemente em todos os conhecimentos! Daí decorre a necessidade de destacar, em qualquer educação, as grandes interrogações sobre nossas possibilidades de conhecer. Pôr em prática essas interrogações constitui o oxigênio de qualquer proposta de conhecimento. Assim como o oxigênio matava os seres vivos primitivos até que a vida utilizasse esse corruptor como desintoxicante, da mesma forma a incerteza, que mata o conhecimento simplista, é o desintoxicante do conhecimento complexo. De qualquer forma, o conhecimento permanece como uma aventura para a qual a educação deve fornecer $o$ apoio indispensável (Morin, 2000, p. 31).

Uma aventura como desintoxicação problematiza o universo das certezas. As múltiplas relações que se estabelecem nos ambientes escolares dizem que as urgências a que precisamos estar atentos, na maioria das vezes, demanda abandonarmos as verdades dos conhecimentos disciplinares, nos lançando em suas minúcias diárias, pensando-as com os mais simples acontecimentos que nos cercam. Exercendo uma "Atenção-cuidado em educação, como uma afirmação à vida, ao que se passa nela" (Dalmaso \& Rigue, 2020, p. 37). Dito de outro modo, não basta sabermos resolver questões que explicam o que é uma pilha e que princípio ela responde, mas sim compreendermos onde a encontramos, como a descartamos e como ela nos afeta na vida diária.

Para Edgar Morin (2005), “[...] a vida é um feixe de qualidades emergentes resultantes do processo de interações e de organização entre as partes, interações, processos, parciais e globais que o produziram" (p. 262). Sem mergulhar nessa complexidade, a compreensão da vida e dos conhecimentos disciplinares revela-se fragmentado e maçante, sem nenhum sentido e significado para produzir uma implicação na vida, no que é vivo.

Pensar a formação de crianças e jovens, bem como, os demais agentes que atuam na escola - dentro da complexidade - é um convite para oxigenar o que se encontra intoxicado de certezas/verdades/saberes/paradigmas. Certezas que nos são cobradas dentro de uma lógica de rendimento que atenta para a educação como mera produção de resultados - que alimentam rankings por meio de escores.

Para Edgar Morin (2005), "Toda teoria dotada de alguma complexidade só pode conservar sua complexidade à custa de uma recriação intelectual permanente” (p. 336). A postura da complexidade, de certa forma, é o que nos faz despertar e levar a explorar tudo, mas não nos permite explicar tudo. Assim, “O pensamento complexo é o pensamento que, equipado com princípios de ordem, leis, certezas e ideias claras, patrulha o nevoeiro, o incerto, o confuso, o indivisível, o indecidível” (Morin, 2005, p. 231). Esse pensar complexo aponta para a importância da incerteza na busca de uma compreensão mais ampla dos conhecimentos que são desenvolvidos nas escolas. Incerteza como "Afirmar a vida em educação implica dar passagem a uma vontade de potência de lançar-se ao incerto" (Dalmaso \& Rigue, 2020, p. 37). 
Research, Society and Development, v. 9, n. 10, e6909109163, 2020

(CC BY 4.0) | ISSN 2525-3409 | DOI: http://dx.doi.org/10.33448/rsd-v9i10.9163

É por isso, que a complexidade nas vivências escolares é um desafio - inclusive quando estamos falando da docência. Ela precisa respeitar as tramas e as articulações que dizem do aprender de cada um que está na escola, levando em consideração suas diferenças, particularidades, singularidades.

[...] complexus é o que está junto; é o tecido formado por diferentes fios que se transformam numa só coisa. Isto é, tudo se entrecruza, tudo se entrelaça para formar a unidade da complexidade; porém, a unidade do complexus não destrói a variedade e a diversidade das complexidades que o teceram (Morin, 2005, p. 188).

A complexidade significa “[...] a união entre a unidade e a multiplicidade” (Morin, 2000, p. 38), entre as diferentes particularidades que compõe as atividades educacionais. Por sua vez, é preciso cuidar que "[...] a complexidade não é só pensar o uno e o múltiplo conjuntamente; é também pensar conjuntamente o incerto e o certo, o lógico e o contraditório, e é a inclusão do observador na observação" (Morin, 2014, p. 206). Essa postura de um pensamento complexo demanda repensar os modos de pensar como compartilhamos com as gerações os conhecimentos desenvolvidos pelas diferentes ciências. Acerca disso Morin (2014) considera o seguinte "A ciência tem necessidade não apenas de um pensamento apto a considerar a complexidade do real, mas desse mesmo pensamento para considerar a própria complexidade e a complexidade das questões que ela levanta para humanidade" (p. 9).

A complexidade no ambiente escolar precisa permitir que não haja a prevalência de pensamentos fragmentados e unilaterais, composto apenas de uma noção de verdade, degradado da razão, ligado e controlado por estruturas incapazes de reconhecer e conceber a multiplicidade do real trincando o próprio conhecimento.

O pensamento simplificador encontra oposição ao pensamento complexo, tendo como principal armadilha anular as diferenças, sem fazer ligações indispensáveis e vivas para que os conhecimentos tomem sentido e significado. O que queremos dizer é que "[...] a linha de força de uma sabedoria moderna consistiria na compreensão" (Morin, 2005, p. 64), o que diz da necessidade de pensarmos conhecimentos de modo a compreendê-los e problematizá-los, e não meramente acumularmos pela mera transmissão de conteúdos, de ensinagem (Rigue, 2020).

De modo linear e hierárquico o pensamento complexo não se prolifera. O pensamento complexo precisa de um largo espectro para acontecer. Ele precisa de pessoas que intensifiquem suas transformações de modo a destinar seus esforços em uma ação educativa que é atenta e relacional. A qual, demanda de uma busca incessante por diferentes perspectivas de entendimento, seja dos conteúdos a serem desenvolvidos nos componentes curriculares escolares, seja nas estratégias pedagógicas, seja dos processos avaliativos, entre outros - que 
estão no entorno da ação pedagógica do professor.

Em termos históricos o pensamento de Edgar Morin (2000, 2005, 2014, 2015) acerca da Teoria da Complexidade é atual. Em termos territoriais ele acontece distante da realidade do chão da escola brasileira. Contudo, as tramas que compõem seu modo de pensar a complexidade em educação são importantes chances para aprimorarmos nossas práticas que tem sido historicamente produzidas no Brasil.

\section{4. É Possível Desenvolver Olhares e Posturas Complexas em meio a Instâncias Escolarizantes?}

Inspiramos-nos na consideração de Zitkoski \& Trombetta (2014) que afirmam que "[...] é preciso reconhecer a desumanização como realidade, como um fato histórico" (p. 152). Comecemos por aqui.

Nos enredos que antecedem essa etapa do estudo, discorremos acerca de uma noção de historicidade da escolarização no Brasil, tendo como aporte teórico autores que a pensam de modo a tensioná-la permanentemente. Além disso, construímos um esforço significativo para abordar a Teoria da Complexidade de Morin (2000, 2005, 2014, 2015) dando relevo a alguns de seus principais escritos, reconhecidos em boa parte dos centros acadêmicos.

Esse exercício permite apontar o quanto a complexidade que pensa Morin não tem tido a chance de residir e fazer morada nas práticas educativas empreendidas nas escolas, pois, "[...] há um aumento expressivo não só de discursos meritocráticos, mas também de competitividades em todas as instâncias educativas" (Rigue \& Amestoy, 2019, p. 164). Aumentos que alimentam estatísticas e inauguram o crescimento de predominantes reduções quanto à participação, responsabilidade, compromisso e implicação com os múltiplos processos de compreensão do conhecimento. Qualificam-se estratégias quantitativas e medidas de aprendizagem, ao passo que se reduzem as reflexões sobre as concepções dos processos de pensamento dos estudantes, suas dificuldades, seus limites, suas possibilidades.

As disciplinas escolares que compõem os currículos contribuem para a redução da possibilidade do desenvolvimento de um pensar complexo supremacia de um conhecimento fragmentado em disciplinas com frequência é ineficiente para efetivar a ligação entre as partes e as totalidades e deve conceber os objetos em seus contextos, em seus conjuntos. É necessário desenvolver a disposição natural da mente para situar todas as suas informações em um contexto e em um conjunto (Morin, 2015, p. 100-101).

Com base nesse pressuposto, as meras informações científicas que para a criança aparecem como uma estrutura disciplinar, se resume a reprodução de teorias behavioristas em educação. Teorias que são baseadas em estímulos e respostas. Estímulos mecânicos, 
programados, aprioriamente divididos, ordenados por grau de dificuldade. Estímulos, que por meio de respostas precisam ser corrigidos, com intuito de avaliar o acerto e o erro. Estímulos que embora aparentemente demandem do estudante um pensamento mais amplo das questões desenvolvidas em aula, são compostos por uma lógica de aquisição de conhecimento como uma espécie de mercadoria - informação/comunicação (Corrêa, 2006).

A transformação de fluxos de vida em informação se dá por meio dos processos de avaliação e de julgamento, que só tomam como positivo, avaliável e desejável as informações que cada um produz incitado por provas, questionários, preenchimento de formulários, inquéritos. A avaliação, o reconhecimento daquilo que se aprendeu, só considera o que se escreve e se transforma em frase, em matéria escrita, em informação. É um longo processo de submeter cada um a um acúmulo de informação, de material informativo e temas apartados da vida do estudante (Corrêa, 2006, p.39).

Vivemos em uma era planetária onde tudo e todos estão cada vez mais interligados por meio das políticas e tecnologias de informação e comunicação. Não é a toa que a escola tem sido cada vez mais convocada para compor essa nova era planetária - de permanente captura. Há um trânsito que tem caracterizado essa passagem no âmbito dos exercícios pedagógicos realizados nas escolas. Por sua vez, o trabalho íntimo do exercício didático pedagógico do professor ainda aparece como fora dos holofotes do que conhecemos como políticas educativas em nível nacional.

Dizer isso deixa explícito que há uma preocupação maior em prescrever orientações dorsais de uma escolarização, ao contrário de prestar atenção para como de fato os professores e professoras mobilizam os conhecimentos na escola (Rigue, 2020), como tem sido para eles fazerem o conhecimento ser mobilizado a partir do que encontram como desafios da prática profissional na educação escolar.

Em termos Didáticos e Metodológicos, temos tido uma manutenção da dissociação entre os interesses e técnicas pedagógicas nominalmente explicitadas nos programas de formação inicial de professores e os problemas efetivos encontrados no exercício profissional. (...) Narrativas e mais narrativas, prescrições e mais prescrições. Ensinar não implica necessariamente em aprendizagem, mas em ser ensinado (Rigue, 2020, p. 242).

Morin (2015) nos ensina que “[...] viver não é apenas ensinar a ler, escrever, calcular, nem apenas ensinar os conhecimentos básicos úteis da História, da Geografia, Ciências Naturais" (p.18), isso porque este ensino ultrapassa dados quantitativos e especializações, adentrando a introdução de "[...] uma cultura de base que implica o conhecimento do conhecimento" (Morin, 2015, p.18). Por sua vez, levando em conta a quantidade exacerbada de 
quadro de conteúdos que os professores precisam dar conta na sua atividade pedagógica, é possível perceber o quanto a mobilização de um conhecer complexo é dificultado, como podemos verificar a seguir:

Essas problemáticas que inviabilizam, na maioria dos casos, a realização de estratégias pedagógicas no contexto escolar são agravadas quando percebemos isso tudo atrelado ao seguinte discurso: 'você pode fazer qualquer outra 'coisa' que ultrapasse o estabelecido, desde que dê conta do que está previsto no conteúdo programático que respeita todas as normas, leis, orientações, dos documentos oficiais'. Essas questões dizem do quanto o trabalho pedagógico empreendido pelo professor em sala de aula encontra-se enclausurado dentro da promessa de que todo ensino precisa e pode ser convertido, invariavelmente, em aprendizagem na escola. Contingência que retroalimenta o âmbito do dualismo ensino-aprendizagem, bem como todas as suas engrenagens e dispositivos que estabelecem uma subjetivação como a hegemonia de estratégias pedagógicas desconexas da vida das crianças e dos jovens (Rigue, 2020, p. 262-263).

A partir do que sinaliza Rigue (2020) quanto a prevalência de um discurso que desloca a importância de um fazer pedagógico complexo e vinculado a existência das crianças e jovens, é latente nesse estudo a necessidade de retomar a vida que habita nas relações que empreendemos em educação, as quais temos abandonado em prol da produção de noções educativas que reduzem o trabalho educacional ao cumprimento de tarefas e o ensino de conteúdos préestabelecidos (Corrêa, 2006). Produzir um movimento que nos coloque enquanto agentes ativos de olhares e posturas complexas em meio a instâncias escolarizantes que tem produzido o apagamento de um pensar ativo e vivo na educação.

\section{Considerações Finais}

Nesse estudo, realizamos um empenho bibliográfico (André, 2013) que teve como cerne tensionar um desenvolvimento de olhares e posturas complexas em meio a instâncias escolarizantes. Lançamos mão da Teoria da Complexidade de Edgar Morin (2000, 2005, 2014, 2015) para tensionar a escolarização e o quanto não temos tido a chance de pensar as questões que emergem na vida que acontece na escola, das crianças e dos jovens, dos professores e professoras.

Principalmente com Corrêa (2006), Corrêa e Preve (2011) e Rigue (2017, 2020), traçamos algumas constatações acerca da escolarização que nos dão alicerce teórico para afirmar o quanto nossas práticas escolares dificilmente têm a chance de produzir um olhar complexo e uma postura complexa no cotidiano. Isso não significa totalizar essa argumentação a todos os cantos do Brasil, a todas as práticas, ao contrário, que olhares e posturas complexas acabam sendo reduzidas a atitudes particulares empenhadas por professores e professoras de modo 
isolado nas escolas.

Pensando isso, em nível nacional, nos parece preocupante delegar inevitavelmente a situações isoladas o desenvolvimento de conhecimentos significativos e complexos a vida das crianças e dos jovens. A proliferação de saberes úteis a formação de vidas humanas precisa estar constantemente latente nas práticas educacionais, sem que a série de garantias da escolarização (De la fare \& Corrêa, 2015) acabem prevalecendo ao caráter pedagógico, criativo e inventivo de formação dos estudantes - dos mais diferentes níveis na escola.

Consideramos que as garantias da escolarização sinalizadas pelo estudo de De la fare \& Corrêa (2015) dificultam o desenvolvimento de um olhar e postura complexa na educação escolar, despotencializando a compreensão de uma aprendizagem mais significativa no contemporâneo, limitando a formação humana, ativa e viva dos estudantes na escola. Ao mesmo tempo, em que tornam a possibilidade de um fazer docente diferencial, potente e complexo cada vez menos possível e cabível de ser realizado.

Emerge desse estudo a necessidade de revermos, permanentemente, as naturalizações que pairam sobre o funcionamento da engrenagem escolar. O quanto isso é indispensável para que seja possível, mesmo que minimamente, desenvolver olhares e posturas complexas em meio a instâncias escolarizantes.

\section{Referências}

André, M. E. D. A. de. (2013). Estudo de caso em pesquisa e avaliação educacional. Brasília: Liber Livros.

Corrêa, G. C. (2000) O que é a escola?. In: Oly Pey, M. (Org.). Esboço para uma história da escola no Brasil. Rio de Ja-neiro: Achiamé, 51-84.

Corrêa, G. C. (2006). Educação, comunicação, anarquia: procedências da sociedade de controle no Brasil. São Paulo: Cortez.

Corrêa, G. C., \& Preve, A. M. H. (2011). A educação e a maquinaria escolar: produção de subjetividades, biopolítica e fugas. Revista de Estudos Universitários, 37(2), 181-202.

Dalmaso, A. C., \& Rigue, F. M. (2020). O Convite da atenção e seus efeitos em educação: entre labirintos, feitiçarias e cuidados. In: Neuscharank, A., Halberstadt, I. A., \& Zanatta, J. M. (Orgs.). Possibilidades... aprendizagens, experiências e gestão na educação, p. 19-40. 
De La Fare, M., \& Corrêa, G. C. (2015). A EJA como analisador de práticas educacionais em contextos de expansão da escolaridade. Educação Por Escrito, 6(2), 339-352.

Foucault, M. (2015). Microfísica do poder. Rio de Janeiro: Paz e Terra.

Morgenstern, J. M., \& Camillo, C. R. M. (2018). Tecnologia do exame: desdobramentos para educação. In: Lunardi-Lazzarin, M. L., Menezes, E. P., \& Lazzarin, L. F. Diferença, educação e cultura: ressonâncias na escola contemporânea. Curitiva: Appris.

Morin, E. (2000). A inteligência da Complexidade. São Paulo: Petrópolis.

Morin, E. (2014). Ciência com Consciência. Rio de Janeiro: Bertrand Brasil.

Morin, E. (2015). Ensinar a Viver- Manifesto para Mudar a Educação. Porto Alegre: Ed. Sulina.

Rigue, F. M. (2017). Uma Genealogia do Ensino de Química no Brasil. Dissertação de Mestrado, Universidade Federal de Santa Maria, Santa Maria, RS, Brasil.

Rigue, F. M. (2020). Uma Genealogia da Formação Inicial de Química no Brasil. Tese de Doutorado, Universidade Federal de Santa Maria, Santa Maria, RS, 2020.

Rigue, F. M., \& Amestoy, M. B. (2019). Práticas educativas nas ciências da natureza: BNCC enquanto emergência do final do século XXI. In: Brancher, V. R., \& Biazus, P. H. S. Caminhos possíveis à inclusão IV: Gênero, educação e humanização. Curitiba: Brazil Publishing.

Rigue, F. M., Amestoy, M. B., \& Veiga; A. M. da R. (2019). Contexto do professorado no Rio Grande do Sul: o desgaste da profissão docente em tempos adversos. In: Machado, G. E., \& Oliveira, V. M. F. de. Temas emergentes a educação: docências em movimento no contexto atual. São Paulo: Pimenta Cultural.

Zitkoski, J. Jo., \& Trombetta, S. (2014). Freire e Dussel: uma pedagogia da libertação a partir da América Latina. In: Freitas, A. L. S., Ghiggi, G., \& Pereira, T. I. Paulo Freire: em diálogo com 
outros(as) autores(as). Passo Fundo: Méritos.

Porcentagem de contribuição de cada autor no manuscrito

Celina Saideles Pires - 50\%

Fernanda Monteiro Rigue - 50\% 